\title{
MUJERES MIGRANTES LATINOAMERICANAS EN ALEMANIA: ENTRE LAS FRONTERAS NACIONALES, DE GÉNERO, ÉTNICAS Y RACIALES ${ }^{1}$
}

\author{
BERENICE HERNÁNDEZ \\ FU-Berlín (Alemania).
}



\section{RESUMEN}

1 siguiente análisis tiene dos objetivos principales. El primero es ubicar la participación de mujeres migrantes del "Tercer mundo" como agentes sociales y políticas en la diversidad de procesos sociales migratorios en épocas de globalización, en contraposición con la imagen de migrantes indirectas, promovida por algunos estudios de migración. Un segundo, es mostrar el cómo éstas -en su calidad de "mujeres/extranjeras/tercermundistas"- son expuestas a situaciones de discriminación y estigmatización social en un orden jerárquico global, definido por fronteras nacionales, de género, etnicistas, y raciales. Ofreciendo como ejemplo el estudio de caso de los procesos de migración de mujeres latinoamericanas a Alemania.

Palabras clave: mujer y migración, Alemania, desigualdades de género.

\section{MIGRACIÓN COMO PROCESO SOCIAL Y MIGRANTES COMO AGENTES SOCIALES Y POLITICO(A)S}

Diversos estudios se han encargado de demostrar cómo la migración internacional no es un fenómeno nuevo sino que más bien se ha ido desarrollando a través de una serie de procesos e intereses económicos, sociales y geopolíticos, en contextos históricos específicos (Castles and

\footnotetext{
Las siguientes descripciones se basan en varios tipos de observación y análisis. El primero es la presentación de algunas reflexiones y resultados preeliminares de la investigación doctoral que realizó en la Universidad Libre de Berlín bajo el tema «Migración, género y ciudadanía. Influencia de los procesos de migración en el caso de las mujeres latinoamericanas migrantes en Berlín». Un segundo es el recogido a través de la asesoría psicológica que he ofrecido desde el 2001 en el marco de una organización de apoyo a migrantes en Berlín (El patio e.V.). La experiencia personal ha sido otro elemento que me ha permitido acercarme a la situación de mujeres migrantes en Alemania.
} 
Davidson 2000, Sassen 2000, Agrela 2002). Así, en la globalización -entendiéndola más allá del orden puramente económico sino también geopolítico, tecnológico e informativo- (ver Castells, 2000) los movimientos migratorios se caracterizan por su incremento, la diversificación de sus modelos, la búsqueda de destinos alternos y el cambio de su composición (Castles/Davidson, 2000, Mezzadra, 2001).

A menudo, los factores para el movimiento geográfico de las personas se simplifican en los discursos dominantes sobre migración y migrantes a factores económicos. Desde esta perspectiva, la migración es vista como una consecuencia lógica del movimiento del capital en la globalización y los migrantes como personas quienes son motivados y/o expulsados como resultado de condiciones económicas (Moulier 2002). Además, estos factores económicos que impulsan a la migración suelen ser re/presentados desde un ángulo unilateral, y preescritos en un marco de conflictos de naturaleza local. Migración se analiza entonces como consecuencia de crisis económicas, desempleo y sobrepoblación, en un contexto de administración ineficaz e inadecuada impartición de justicia que aquejan a la mayoría de países del "Tercer Mundo" o "en vías de desarrollo" ubicados mayoritariamente en Latinoamérica, Asia o África. Factores que además son expuestos como independientes y no como un resultado de las jerarquías del orden estructural existentes en la globalización.

Diversas perspectivas han cuestionado esta tradición economicista en la investigación (ver p.e. Sassen 2000, Medrazza 2001, Moulier 2002) por reducir este complejo proceso a un análisis focalizado y limitado. Reducción que, entre otros aspectos, conduce a la asociación de los procesos de migración actuales casi como sinónimo de migración laboral, y a migrantes sólo como migrantes económico(a)s. Como respuesta, se han expuesto estudios sobre las redes sociales de migrantes, a partir de las cuales se comprueba que no sólo factores de atracción económica mueven a los y las migrantes hacía los países receptores, sino también la permanencia y recreación de redes sociales de éstos y éstas con sus lugares de origen, como resultado de procesos históricos y sociales de la propia migración. Cuestionando también el análisis dual de la migración internacional como expulsión/atracción, origen/destino, con una visión lineal de cambio que impide observar la multiplicidad de historias individuales y colectivas que ocurren en los procesos sociales migratorios. La migración vista entonces desde esta perspectiva ${ }^{2}$ no es consecuencia

2 A veces esta noción puede ubicarse como "transnacional" (Massey 1987, Smith 1995, Pries 1998 cit. por Velasco 2002), aunque pienso que no necesariamente siempre se ubica bajo este nombre (Moulier 2002, Medrazza 2001, Sassen 2000, Castles and Davidson 2000). Se trata generalmente de un enfoque que recupera un contexto de análisis de las interacciones globales, poniendo especial énfasis en el papel de los Estados nacionales, al mismo tiempo que busca la recuperación de las historias-colectivas e individuales-de los y 
única del movimiento de capital, sino que se muestra como un proceso social, y los migrantes como agentes sociales y político(a)s, que participan y la construyen de forma activa (Moullier, 2002). Activando un potencial de transformación y de búsqueda de cambio mediante precisamente su proceso de migración. Deseo y acción a través del cual se posicionan en el papel de agentes sociales y político(a)s $\mathrm{s}^{3}$.

Actualmente, la exposición simplificada de factores que se involucran en la movilidad de personas, conlleva por un lado a una carencia en la comprensión sociológica y política de la migración en un contexto actual, denotando una incapacidad analítica para vincular adecuadamente el impacto estructural que tiene en diferentes niveles -sociales, geopolíticos, culturales- el orden económico y tecnológico a nivel global (Castells 2000). Además, se invisibiliza la dimensión social y subjetiva que se involucra en ellos, como, por ejemplo, las redes sociales transnacionales, circuitos, organizaciones y agentes migrantes como estructuradore(a)s del orden social. Por otro lado, sustenta la re/producción de estereotipos y la estigmatización de migrantes en las sociedades dominantes receptoras, con un reflejo directo en las políticas y leyes migratorias, propiciando la imagen de los y las migrantes del Sur como una "amenaza" para los países con dominancia política y económica, donde la migración y sus actore(a)s son re/presentado(a)s como un peligro, que atenta contra los sistemas de bienestar social, los puestos de trabajo de lo(a)s ciudadano(a)s, y la seguridad nacional (Sassen 2000), al mismo tiempo que su diferencia cultural es vista como atentante para una imaginada identidad unitaria nacional (en alusión a Anderson 1988), en lugar de analizarse como un proceso social que puede conllevar a repensar conceptos nacionalistas, racistas y sexistas en el marco de la migración internacional, los Estados nacionales y la ciudadanía actual.

\section{PARTICIPACIÓN DE MUJERES MIGRANTES Y FEMINIZA- CIÓN DE LA MIGRACIÓN}

Acompañada de una diversificación de los movimientos sociales migratorios y un aumento en la complicidad de su composición en la globalización, se observa no sólo una creciente participación de las mujeres en los procesos migratorios sino incluso una mayoría femenina

las migrantes en la construcción de un campo social que vincula sus experiencias durante el proceso migratorio en contextos geopolíticos, sociales, culturales y económicos específicos.

3 El concepto de agente se diferencia del de sujeto porque supone la capacidad de los individuos para modificar las estructuras sociales objetivas o para crear otras nuevas (Touraine 1995, Bourdieu 1990, 1995, Guidens 1979, 1995 cit. por Velasco 2002), optando entre varias opciones posibles (Guidens 1995, ibid). Además, Moulier (2002) reconoce en esta agencia para el caso de migrantes, no sólo su carácter social, sino también político -a través del deseo y la actividad migratoria- en la busqueda de un cambio. 
en la migración transnacional. Este fenómeno se ha dado en llamar feminización de la migración, y con él se busca describir la participación mayoritaria de las mujeres en los movimientos sociales migratorios.

La participación y el rol de las mujeres por mucho tiempo no ha sido temática de interés dentro de los estudios y teorías de migración (Prodolliet 1999, Ariza 2000, Schöttes/Treibel 1997, Aufhauser 2000, Hanh 2000, Woo 1996). A lo largo de las tres últimas décadas, gracias a la insistencia de investigadoras con perspectiva de género, investigadoras y colectivos de mujeres Negras ${ }^{4}$ y/o migrantes, se ha ido incorporando lentamente la participación y el rol de las mujeres en los estudios de migración ${ }^{5}$. Sin embargo, se puede decir que hasta hoy en día la participación de las mujeres así como la forma en que la variable género interviene en la migración, han quedado todavía marginadas dentro de las investigaciones, predominando la imagen de las mujeres sólo como sujetos pasivos, amantes de su entorno, sin toma de decisiones y acompañantes del verdadero sujeto de estudio: el migrante masculino (Prodolliet 1999, Ariza 2000, Schöttes/Treibel 1997, Hahn 2000).

Principalmente investigadoras migrantes y/o mujeres Negras discuten también las imágenes de "la migrante" que se promueve en la investigación de la migración e incluso desde la investigación de género realizada por mujeres pertenecientes a las sociedades dominantes. Se critica la forma en que se refiere y construye sobre todo a mujeres migrantes provenientes del "Tercer mundo", interpretándolas a ellas y a sus

4 Con la utilización de la mayúscula se busca anunciar la utilización política del término. "Negras" no busca describir características biológicas diferenciadas, sino con su uso se intenta dar cuenta de las construcciones sociales -materiales y subjetivas-alrededor del color de piel como característica de diferenciación, estructuración y organización social jerárquica. Con el posicionamiento político como mujeres "Negras", se busca denunciar la construcción y constitución de prácticas y discursos racistas propios de nuestras socicdades actuales y sus instituciones con un pasado y huellas coloniales.

5 Perteneciente a lo que ha sido en llamar la primera generación en los estudios de migración con una perspecliva de género que aproximadamente se registra entre los años 70 y 80 (Ariza 2000, Gutiérrez 1999), como una primera tarea se busca incorporar la participación femenina, realizando un trabajo compensatorio a los estudios Mainstream de migración debido al hueco existente al omitir el rol y la participación femenina. Una segunda generación intenta indagar en la forma en que la categoría de género incide hacia una desigualdad en el ámbito social, destacándose por ejemplo la relación entre migración y mercados de trabajo y/o su impacto en la unidad doméstica (Ariza, 2000). Ambas generaciones constatan que mujeres migrantes son protagonistas de acción y decisión en todo su proceso migratorio (Velasco 2002, Prodoliet 1999, Ariza 2000, Aufhauser 2000). A mitad de los 80, principios de los 90, se puede hablar, según Prodolliet (1999), de un ensanchamiento teórico de los estudios de migración con perspectiva de género. En esta conocida como tercera generación o etapa, se analiza no solamente el rol de las migrantes como eje de análisis, sino lentamente se incorpora la incidencia del género en todo el proceso migratorio, su entrecruzamiento con otras categorías como la etnia, la clase, "raza", preferencia sexual, etc. (Morokvasic 1987, Gutiérrez [999, 2003), asi como otras jerarquías de poder, como las existentes entre Sur/Norte.

6 La construcción social de la categoría "Primer mundo/tercer mundo" bajo la visión occidental dualizada de la realidad social, logra la construcción de la "mujer/tercermundista" y su contraste con las mujeres occidentales. Mohanty comenta: This average Third World woman leads an essentially truncated life based on her feminine gender (read: sexuality constrained) and her being "Third World" (read: ignorant, poor, uneducated, tradition-bound, domestic, family-oriented, victimized, etc.) This, I suggest, is in contrast to the 
procesos migratorios a través del paradigma de modernidad/tradición. Las mujeres migrantes no son temática de interés común en los estudios de migración y, si lo son, --afirman investigadoras migrantes y/o $\mathrm{Ne}$ gras- éstas suelen aparecer interpretadas como víctimas de sociedades fuertemente tradicionales y patriarcales, obstaculizadas de su acceso al espacio público en sus lugares de origen, heterosexuales y homogenizadas, fuertemente apegadas a estructuras de género y/o escenificadas en la figura de la ama de casa. La migrante "casada con", "trasportada" o "traficada" por un hombre perteneciente a la sociedad «moderna" dominante, suele ser objeto común de investigación (Morokvasic 1987, Apitzch 1996, Gutiérrez 1999/2003, Ulmut Erel 2003, Hernández 2000, 2003, Andrijasevic 2004, Haritaworn 2003, entre otras).

Contrariamente a la predominante idea centrada en el sujeto migrante masculino o a la supuesta "pasividad" femenina, las estadísticas demuestran que las mujeres participan en la migración en mayor medida que los hombres: las mujeres participan en la migración interna, continental y transcontinental. Internacionalmente son poco más del $50 \%$ de la población migrante y conforman entre el $70 \%$ y $80 \%$ de la población de refugiados y asilados del mundo (Schöttes/Treibel 1997). En Europa en 1990 las mujeres conformaban ya el 46,3\% de la población de extranjeros (Sassen 1996: 213 cit. por Le Breton, 1999). En los Estados Unidos en los mismos años eran más de la mitad de la población migrante (Le Breton, 1999). Contrario a la imagen de acompañantes y de apego a sus estructuras familiares patriarcales, un gran porcentaje de mujeres del "Tercer mundo" viajan solas y, en muchas ocasiones, dejando a sus hijos al cuidado de sus madres, familias o de sus maridos, en el caso de tenerlos.

Importante apuntar respecto a estos datos que la proporción de mujeres migrantes respecto a la de los hombres varía, tanto de los países receptores como en cuanto a los lugares de procedencia. Así, aun cuando son poco más de la mitad total de la población de migrantes, estos datos pueden variar de país a país. Por ejemplo, según investigaciones de Balding, Euler, Hanmer, Wigglesworth en la Universidad Metropolitana de Leeds ${ }^{7}$, en Islandia, Irlanda y el Reino Unido el número de mujeres inmigrantes supera en mucho al de hombres; en Portugal, Alemania $^{8}$, Italia y Austria el número de hombres inmigrantes supera por

(implicit) self-representation of Western women as educated, as modern, as having control over their own bodies and sexualities, and the freedom to make their own decisions (Mohanty, 1991).

7 Datos de la pág. «La circulación de mujeres. Ciudadanía, migración y procesos de integración europea de la Universidad Metropolitana de Leeds». www.helsinki.fi/science/xantippa/wes/wes $24 . h t m 1$

8 En Alemania, según los datos de la Oficina de Estadísticas (Statistisches Bundesamt, Ausländische Bevolkerung nach der Staatsangehörigkeit am 31. 2002 in Deutschland, 2002.) en el 2002 el número oficial registrado de mujeres extranjeras era de 3.408 .900 , mientras que el de hombres de 3.926 .700 . 
poco al de mujeres. Entre los inmigrantes de la India, Polonia, Suiza, Estados Unidos y Filipinas, el número de mujeres supera constantemente al número de hombres. La proporción de mujeres filipinas para con sus compatriotas masculinos es de uno por tres (Val Balding, Catherine Euler, Jalna Hanmer, Debbie Wigglesworth, Ibid).

En los todavía escasos estudios sobre la migración de mujeres latinoamericanas a Europa, por ejẹmplo, se puede observar cómo las mujeres representan una mayoría significativa frente a los hombres. De la comunidad de migrantes del Perú en Barcelona, las mujeres conforman el 80\% (Escriva 1996 cit. por Aufhauser 2000). Cerca de 7.000 mujeres de Vicente Robles, una pequeña ciudad en la República Dominicana de aproximadamente 25.000 habitantes, trabajan en Madrid; la cantidad de hombres que abandonaron esta comunidad durante los 90 no llegaba a los mil (Leuthold 1898, Ibid.). Gregorio Gil (2002) arguye una mayoría femenina de mujeres provenientes de Colombia, Perú y República Dominicana en España. Estudios de caso no publicados muestran la misma tendencia en el caso de Italia9. En el caso de Alemania se observa también que el porcentaje de mujeres en las estadísticas oficiales llega al $68 \%$ frente a la población masculina proveniente de Latinoamérica ${ }^{10}$, es decir, duplican a la población masculina (Statistisches Bundesamt, Ausländische Bevolkerung nach der Staatsangehörigkeit am 31. 2002 in Deutschland). Así, la migración latinoamericana a Europa da cuenta de una feminización.

Además de los términos cuantitativos, se ha buscado, desde la perspectiva de género, incluir la diversidad de procesos migratorios en que participan mujeres. Un desgloce de formas y motivos de migración, realizado por Schöttes y Treibel en 1997, arroja que las mujeres migran por necesidad existencial, para asegurar su supervivencia y/o la de familares, por deseos de aventura, de cambio, por la búsqueda de un nuevo lugar de pertenencia, por estudios y también como expertas, así como por la violencia que se genera contra ellas por su pertenencia a un determinado grupo ya sea éste político, religioso, étnico, lazos familiares con la oposición y por transgredir reglas específicas destinadas para mujeres.

9 Gracias a la participación en el Congreso "I Latinos alla scoperta dell” Europa. Nuove migrazioni e suazi della cittadinanza" llevado a cabo en la Universidad de Génova en junio del 2004, tuve la posibilidad de compartir mis resultados de investigación con otros, que me confirmaron también la presencia mayoritaria de mujeres latinoamericanas en Italia.

10 Cabe señalar también que estos datos contemplan solamente a los y las migrantes registrados oficialmente. Aquellos migrantes en una situación irregular no pueden ser contabilizados, así como tampoco se contemplan en estos datos a quienes ya han adquirido la ciudadanía del país receptor. Sin embargo, es un hecho que las mujeres también participan en gran medida de la migración ilegalizada y que el estereotipo todavía prevaleciente del «migrante masculino ilegalizado» forma parte de la marginación de la participación femenina en los movimientos migratorios. 
De esta forma, las mujeres son protagonistas de acción en la diversificación de los movimientos migratorios en la globalización. Ellas participan tanto en la migración voluntaria como en la forzada. Son parte de la migración interna, transnacional y transcontinental, de la migración temporal (sojourners) y permanante (settlers), así como de la migración legal e ilegalizada". Su migración puede ser laboral, por reunificación familiar y por redes sociales migratorias, intelectual, en busca de refugio y asilo e impactadas también por imágenes promovidas por la globalización. Se registran también la búsqueda de nuevas experiencias, espacios de convivencia y culturas. Así, la figura de la migrante como "acompañante pasiva" pierde válidez cíentífica y social.

\section{NACIONALIDAD, GÉNERO,"RAZA"Y ETNICIDAD}

Como se muestra, las mujeres son agentes sociales en su proceso de migración. Su participación en los movimientos migratorios en épocas de la globalización responde a factores variados, así como también es heterogénea y sus modelos son diversificados, como en el caso de la migración masculina. Sin embargo, en su caso específico, estoy de acuerdo con autoras como Chant (1992), quien afirma que el género es un principio organizador fundamental en la estructuración de los flujos migratorios. Así, las todavía existentes asimetrías entre hombres y mujeres propician situaciones de desventaja para estas últimas, que cuestionan de diversas maneras sus necesidades de supervivencia económica, social, política y/o cultural.

Por ejemplo, para el caso de las mujeres del Sur ${ }^{12}$, el hecho de que el $70 \%$ de los pobres del mundo sean mujeres, y que por razones estructurales y no unilaterales, la mayoría de gente en condiciones de pobreza se concentre en estos países. Este fenómeno conocido como feminización de la pobreza no responde a que ellas no participan dentro de la población económicamente activa, sino al inequitativo acceso que tienen al mercado de trabajo, derechos, bienes y recursos. Lo que adquiere forma práctica en su participación dentro de la economía informal, los

11 Utilizaré el término ilegalizado(a)s (Illegalizierte) o ilegalización (Illegalisierung) de la discusión alemana en vez de el de "san papiers" de la discusión francesa, o "indocumentado(a)s" de la latinoamericana o estadounidense, ya que, en mi opinión, el término ilegalizado(a)s describe de mejor forma el proceso de ilegalización que experimentan migrantes -por parte de las Instituciones, prácticas y discursos de las sociedades receptoras-, debido a la carencia de un permiso de estancia otorgado por el Estado nación.

12 Para más informaciones acerca del uso de los términos «tercer mundo/Sur y primer mundo/Norte» (Third World/South and First World/North), así como el de «Un tercio de mundo/dos tercios de mundo» (One-Third World /Two-Thirds World), revisar el análisis de Mohanty (2002). La autora propone el uso de One-Third World versus Two-Thirds World en conexion con Third World/South and Firsi World/Norh, aludiendo con ello a una minoría social o una mayoría social basada en la calidad de vida de personas nacidas ya sea en el Sur o Norte especificados en términos geográficos. 
trabajos de servicio, menor acceso a puestos de trabajo bien remunerados, falta de reconocimiento y salario de su trabajo dentro del hogar, desempleo, a las restricciones legislativas para acceder a los préstamos, propiedad y herencias (Hernández 2003).

En situaciones de conflicto armado y desastre natural, la enorme mayoría de las personas en situación de riesgo son otra vez las mujeres y los niños, quienes en muchos casos representan más del 70\% del total y hasta un $90 \%$ de los afectados (Schöttes/Treibel 1997). En las últimas décadas el porcentaje de mujeres que han abandonado sus lugares de origen a causa de motivos políticos se ha incrementado (Poots 1993, Lutz 1997 cit. por Gutiérrez 1999). Ellas conforman la mayoría de los desplazados, calculados en aproximadamente unos 20 millones de personas a nivel mundial (Gutiérrez 1999). Las mujeres son objeto de persecución en sus lugares de origen a causa de sus actividades políticas, pertenencia a una minoría religiosa o étnica, por sus relaciones familiares con personas de la oposición o por sobrepasar normas y leyes específicas para mujeres (Schöttes/Treibel 1997).

Su pertenencia sexual también es objeto de cuestionamiento y persecución social. La heterosexualidad normativa propia de sociedades actuales puede ser también un motivo para la migración femenina. Aunque la opción sexual como motivo migratorio ha sido escasamente tematizado, algunas mujeres adhieren el lesbianismo como un motivo más para las mujeres para cruzar fronteras (Spin, 1997, Mongrovejo 2003 , cit. por Escalona 2004), confrontándose con una sociedad receptora también heteronormativa, que en su calidad de migrantes las somete a una forma más de discriminación. Anzualda (1987), por ejemplo, describe una realidad de mujer en la migración definida por fronteras múltiples, geográficas nacionales, pero también fronteras sexuales. En su posición de mujer fronteriza, Anzualda incorpora su condición de lesbiana como una forma de discriminación dentro de la literatura de migración.

En ese sentido, pienso que la variable género no es la única variable que estructura aisladamente el proceso migratorio, sino que actúa en entrecruzamiento con otras categorías sociales que implican desigualdad, como la nacionalidad, la construcción de "raza", la etnicidad, entre otras, como la historia colonial y/o la heterosexualidad forzada, etc. Por ejemplo, mujeres lesbianas Negras feministas de Latinoamérica cuestionan las diversas discriminaciones estructurales a las que se ven expuestas como mujeres, "tercer mundistas", negras y lesbianas (Curiel, 2003). También la literatura de mujeres migrantes expone como éstas en su cotidianidad experimentan múltiples discriminaciones simultáneas como no-nacionales/extranjeras, mujeres, trabajadoras, lesbianas, etc. 
Arguyo que estas posiciones sociales de sujeto no aparecen una detrás de otra, sino que se entrecruzan dependiendo del espacio en que éstas, como sujetos sociales, son "solicitadas», ya sea en las sociedades de origen, en las fronteras y/o en las sociedades dominantes de recepción, estructurando y organizando jerárquicamente el proceso migratorio en su totalidad. De esta forma, mujeres migrantes del Sur resultan en su calidad de "mujeres/extranjeras/tercer mundistas" expuestas a situaciones de desventaja y discriminación social en las sociedades dominantes del Norte en un orden jerárquico global definido por fronteras nacionales, de género, etnicistas, y raciales, entre otras. A continuación, ofrezco, a manera de ejemplo,el análisis de caso de la migración de mujeres latinoamericanas a Alemania.

\section{MUJERES MIGRANTES LATINOAMERICANAS EN ALEMA- NIA}

En las últimas tres décadas, la migración latinoamericana al continente europeo ha presentado un aumento significativo. Este fenómeno responde por un lado al endurecimiento de las estrategias en el control del flujo de los y las migrantes latinoamericano(a)s hacia los Estados Unidos, mientras que, por otro, responde también al trazado de direcciones alternas que los migrantes, como actore(a)s sociales de su proceso migratorio, desarrollan para su movilidad espacial en épocas de globalización, siendo un hecho que, a partir de los años 70, la migración transcontinental latinoamericana ha crecido, convirtiéndose Europa en una nueva alternativa migratoria para los latinoamericanos $\mathrm{y}$, sobre todo, para las mujeres latinoamericanas.

La migración de mujeres latinoamericanas a Alemania es un fenómeno social que no ha sido suficientemente estudiado en toda su diversidad. Esto se debe en gran parte a que éstas no representan en términos cuantitativos una población migrante significativa, como lo son en el caso de los Estados Unidos, o en el caso de Alemania lo representan la migración turca. Otro motivo para el escaso estudio de esta migración es que se ha identificado a estas mujeres como migrantes "pasivas", reduciendo su participación en la migración a la reunificación familiar, donde se interpretan como esposas acompañantes de los asilados políticos, intelectuales, o trabajadores, etc. Además, en muchos casos, son interpretadas en el papel de mujeres "transportadas", adjudicándose su migración a la figura masculina europea ${ }^{13}$, es decir, mujeres que son

13 Esta imagen es reforzada también por los medios, como en el caso de la película Heirate mich!/ $C a ́ s a t e$ conmigo!, donde la protagonista de origen cubano llega a Alemania en compañia de su hijo a raiz del matrimonio con un alemán. 
"llevadas" a Alemania por un hombre blanco perteneciente a la sociedad dominante, invisibilizándose así, su papel de actoras sociales en la migración, diversidad de motivos, experiencias y estrategias en sus procesos migratorios.

Sin embargo, mi investigación con mujeres latinoamericanas en Alemania, me ha mostrado que esta población migrante conglomera características que corresponden con las mismas que caracterizan a la migración en épocas de globalización: sus motivos y modelos migratorios son diversificados, trazan un destino alterno al elegir un país europeo frente a la tradicional migración latinoamericana a los Estados Unidos, han cambiado la composición del flujo al dar cuenta del fenómeno de la feminización de la migración, siendo mayoría frente a la población masculina migrante del mismo continente, y, además, en muchos casos, ser mujeres que migran solas.

\section{CARACTERISTICAS Y MOTIVOS}

La migración de mujeres latinoamericanas a Alemania tiene historia. A partir de los años 70 , se nota un crecimiento de esta migración debido a las dictaduras militares en algunos países latinoamericanos. Sobre todo se trató de mujeres argentinas y chilenas, quienes, debido a su propia pertenencia política, o a la de sus parejas, llegaron a Alemania con la intención de pedir asilo político y poner a salvo sus vidas. Durante los 80 , se observa otra migración de mujeres estudiantes nicaragüenses y cubanas, quienes llegaron a la RDA con objetivos educativos. Actualmente, los motivos de esta migración se han diversificado, registrándose las siguientes formas y motivos de migración: migrantes trabajadoras en búsqueda de empleo para mejorar sus propias condiciones de vida o la de sus familias; la reunificación familiar -en la cual cabe el casamiento con un alemán-; las asiladas políticas, destacándose la presencia en los últimos cinco años de las colombianas; la migración intelectual, es decir, mujeres en busca de ámbitos académicos para su especialización. Como podemos observar en las anteriores descripciones, sus migraciones no son motivadas puramente por la reunificación familiar, como tampoco sólo por razones económicas. Resultado también de la globalización es que en constante contacto con imágenes sobre el papel educativo de los viajes y otras culturas, también se registra la presencia de mujeres latinoamericanas quienes migran a Alemania -y en particular a Berlín - por ser ésta conocida como «ciudad alternativa» y «multicultural», motivadas por la búsqueda de viajes y aventuras. 
Contrario a la idea de la migrante secundaria, mi trabajo de campo, además de mostrarme la gama de motivos migratorios de estas migrantes, me arrojó también que muchas de las latinoamericanas que migran a Alemania o a otros países de la Unión Europea lo hacen solas, dejando a sus hijos al cuidado de sus familias y enviando dinero mensualmente desde el extranjero para la manutención en muchos casos de familias enteras. La coordinadora de la organización de mujeres latinoamericanas Xochicuicatl, Stella Dreier, al entrevistarla, comentó al respecto: "[...]hay mucha migración de mujeres y no podría decirte exactamente si son más mujeres que hombres. Pero, de cualquier manera, son muchas mujeres solas, y que han dejado su familia allí, hijo, exmarido, etc. [...]» (Stella Dreier, 26.08.02-02.09.02, Berlín).

Estas mujeres no sólo migran a menudo solas sino que otra característica de esta migración es que, como Dreier supuso, ellas conforman una mayoría, siendo el $64.98 \%$ del total de la población migrante latinoamericana en este país (Statistisches Bundesamt, Ausländische Bevolkerung nach der Staatsangehörigkeit am 31. 2002 in Deutschland), como expuse anteriormente. En el caso específico de la ciudad de Berlín, observando los datos proporcionados por la oficina de estadísticas en 2003, se puede observar que las mujeres conforman el $55.35 \%$ del total de la población migrante latinoamericana. De los países con mayor presencia, como Argentina, Brasil, Chile, Cuba, Colombia, República Dominicana, México y Perú, el porcentaje de mujeres migrantes registradas oficialmente supera al de los hombres, con las únicas excepciones de Chile y Cuba, donde casi conforman la mitad de la población (Statistisches Landesamt Berlin, Melderechtlich registrierte Ausländer in Berlin am 30. Juni 2003 am Ort der Hauptwohnung nach Staatsangehörigkeiten).

Las mujeres latinoamericanas provenientes de diversas culturas y lenguas coexisten con diferentes estatus de residencia o ilegalizadas ${ }^{14}$ dentro de la sociedad alemana. Las diferencias que presentan corresponden en gran parte a la diversidad de mujeres que existe en Latinoamérica. La psicóloga Sonia Solarte, quien asesora a migrantes latinoamericanas en Berlín en el marco de la organización SUSI, comenta sobre su diversidad: «[son]...mujeres de regiones rurales [...], de las capitales, que vienen de una situación de discriminación, que no han vivido situaciones de discriminación, que de alguna manera han tenido posibilidad de movilizarse, a nivel político, que son artistas, que son in-

14. Utilizaré el término "ilegalizado(a)s" de la discusión alemana en vez del de "san papiers" de la discusión francesa, o "indocumentado(a)s" de la latinoamericana o estadounidense, ya que, en mi opinión, el término ilegalizada(o)s describe mejor el proceso de ilegalización que experimentan lo(a)s migrantes - por parte de las Instituciones, prácticas y discursos de las sociedades receptoras- debido a la carencia de un permiso de estancia otorgado por el Estado nación. 
telectuales, $[\ldots]$, que han sido sobresalientes $[\ldots]$...El espectro ha sido inmenso". (Sonia Solarte, 24.10.02, Berlín).

A pesar de la diversidad que presentan, otra característica importante a tomar en cuenta para el análisis de las experiencias de estas migrantes en las sociedades receptoras dominantes es que muchas de ellas poseen estudios medios o superiores. Susanne Schultz (2002, 11.09.02, Berlín), participante de una red en Berlín conformada por alemanas y migrantes latinoamericanas sobretodo ilegalizadas, me comentó al respecto: «... las que llegan aquí normalmente tienen un nivel de educación mayor, han estudiado, han hecho por lo menos una formación técnica. Pero no encuentran aquí trabajo en esto». Además de que ellas en su mayoría no provienen de las clases más desprivilegiadas, sino de clases medias y a veces medio-altas. La misma entrevistada comenta al respecto: "[...]muchas mujeres que llegan aquí pertenecen a la clase media $[\ldots]^{\prime \prime}$.

\section{ENTRE LAS FRONTERAS NACIONALES, DE GENERO, ÉT- NICAS Y RACIALES}

Una mujer migrante proveniente de Perú relata lo siguiente: "para mí fue algo muy nuevo, porque yo en mi país tenía otro trabajo, estudié secretariado computerizado, trabajaba en una compañía grande de cajera. En este país tuve hasta que limpiar baños $[\ldots]^{15 \%}$.

La mayoría de estas mujeres en sus lugares de origen han sido parte de la población económicamente activa, en muchos casos son jefas de familia o por lo menos copartícipes, cuentan con calificaciones académicas medias o superiores, son mujeres emprendedoras que han asumido los riegos de migrar para mejorar sus condiciones de vida, $\mathrm{y}$ algunas han sido figuras protagónicas en movimientos sociales de oposición (Hernández 2003). Es decir, han sido actoras en la construcción de su vida y de su proceso de migración. Sin embargo, una de las observaciones que he realizado en mi investigación es que al insertarse a la sociedad alemana, se ven enfrentadas a diferentes procesos de discriminación y estigmatización social que las coloca en un lugar subalterno ${ }^{16}$ en el orden jerárquico global, derivado de la situación a la que

15 Entrevista en "juniradio" trasmitida el 18 de junio del 2003, con mujeres latinoamericanas ilegalizadas en Berlín, las cuales en el momento de la entrevista ya tenían estancia legal.

16 En alusión a Antonio Gramsci, Spivak (1998), en su conocido ensayo Can the subaltern Speak?, designa como "subalternos' el sometimiento de grupos sociales por parte de grupos hegemoniales (cit. por Gutiérrez. 2003). Este sometimiento social de migrantes, y en especial de mujeres migrantes, se estipula a través de múltiples dinámicas de marginación, demarcadas por el racismo y universalismo inserto en la construcción de los Estados nacionales y los regímenes de fronteras en un contexto de políticas y leyes migratorias, y la persistencia de estructuras jerárquicas del género. 
las expone su calidad de ser «extranjeras», «mujeres» y provenir de los así llamados países del Tercer mundo o países en vías de desarrollo.

En este artículo, por cuestiones de espacio, me ceñiré sólo a describir el acceso que tienen mayoritariamente las migrantes latinoamericanas al mercado de trabajo, por ser uno de los ejemplos más claros -a pesar de no ser el único-, en el cual se pueden observar los procesos de discriminación y estigmatización social que en diferentes niveles experimentan estas migrantes en la sociedad receptora dominante.

Saskia Sassen (1996), en sus análisis respecto a las Global Cities, menciona la necesidad de los trabajos de servicio en la globalización como sostén de los trabajadores hipermóviles especializados y de liderazgo del mercado internacional. Sin este sector laboral desvalorado e invisible nada podría funcionar en la economía mundial. Este sector de trabajo, comenta Sassen, lo llenan mujeres y migrantes principalmente. Sin embargo, las mujeres migrantes realizan dentro del trabajo de servicio el trabajo menor pagado, más flexible y con menos o sin ningún tipo de seguridades sociales. Ellas realizan mayoritariamente el trabajo de limpieza, sirven y cocinan en los restaurantes, cuidan de los niños, de los ancianos y de los enfermos.

Acertadamente, como describe Sassen, el trabajo de investigación con migrantes latinoamericanas en Alemania me ha mostrado que, independientemente de sus estudios y en la mayoría de casos también de su tipo de estatus de residencia, éstas -al igual que muchas otras migrantes en sociedades del Norte-, se ven restringidas a participar dentro de este acceso al mercado de trabajo que les «ofrece» la sociedad receptora. Yo quiero exponer el cómo en ello no sólo mujeres migrantes enfrentan un proceso de desplazamiento social como, por ejemplo, el de descualificación y desclasificación, sino al mismo tiempo también un proceso de discriminación y estigmatización social con fuertes características sexistas, raciales y de etnización.

Este mercado de trabajo que se «ofrece» a mujeres migrantes se caracteriza por tener un mayor apego a las estructuras tradicionales de género, ya sea por desarrollarse dentro o alrededor de la esfera doméstica (limpieza, cocina) o definirse por el cuidado de los otros (niñeras). Actualmente, la esfera doméstica de las mujeres nacionales de los países dominantes se ha convertido en el acceso al «espacio público» de las mujeres migrantes. Así, formas de discriminación de género en relación al acceso de mujeres al mercado de trabajo no han sido suprimidas, sino solamente se han desplazado a mujeres migrantes de Asia, América Latina, Africa y Europa del Este. 
Además, los discursos y características alrededor de mujeres migrantes provenientes del "Tercer Mundo" que se construyen en las sociedades de destino dominantes juegan un papel importante para dicha inscripción social. Estas características pueden también presentar variaciones según los estereotipos asignados a cada comunidad de migrantes (por ejemplo, se esperan diversos comportamientos de mujeres asiáticas, latinoamericanas o mujeres turcas). Este fenómeno ha sido denominado por Gutiérrez (1999) como etnización y describe la dinámica de determinar a un grupo de personas dentro de una estructura de reconocimiento, atribuyéndoles características específicas. Los y las participantes tienen que aceptar dichas características para ser reconocida(o)s, aunque éstas no tengan que ver con ella(o)s.

De esta forma, trabajos de limpieza, cocina y cuidado de niños se ofrecen preferentemente a migrantes que, como las «latinas», comparten en las representaciones de la sociedad de destino la asociación con características, respecto a su género y origen cultural, de ser mujeres "amantes del hogar, limpias, amorosas con los niños, buenas cocineras, serviciales frente a la figura masculina", etc.

Consecuencia también de procesos de discriminación y estigmatización social con características sexuadas, racistas y étnicas es que de acuerdo con el estereotipo de mujeres latinoamericanas -y especialmente de mujeres negras-, como sexualmente "fogosas", "dispuestas", "temperamentales", también puede ocurrir que, como una extensión de sus servicios domésticos, los empleadores esperen de sus empleadas que desempeñen servicios sexuales. Un indicio de ello es que muchas migrantes latinoamericanas, cuando colocan anuncios para buscar trabajo en los periódicos en Alemania, se ven obligadas a especificar que sus servicios no incluyen actividades sexuales: "Sudamericana busca trabajo para limpiar o cuidar niños. Lunes a viernes, y tambien fin de semana. Ningún sexo!" o "Joven mujer de Brasil busca trabajo como doméstica. Limpieza profunda y confiabilidad. Sólo propuestas serias" (Zitty, 30.10.-12.11.03). Otro ejemplo de ello es que, en las representaciones sexuales masculinas de los nacionales, los cuerpos de estas migrantes se convierten en objeto de deseo a través de su exotización. El sexo servicio es también un mercado de trabajo ocupado mayoritariamente por mujeres migrantes (Rosina, 2000) - ya sea de manera forzada o voluntaria-. Dentro de este tipo de trabajo, las migrantes latinoamericanas son demandas a partir de las características sexuales con que son asociadas, dándose lugar a la exotización de su cuerpo. Una estrategia colectiva de estas migrantes para protegerse de los abusos que, en su calidad de mujeres y extranjeras, pueden presentarse dentro 
del trabajo de sexo servicio, es la organización Doña Carmen con sede en Frankfrut/Main.

Estos procesos de discriminación y estigmatización social que enfrentan las mujeres migrantes latianoamericanas al llegar a Alemania se pueden observar en los diversos espacios de interacción de su vida cotidiana en las sociedades de recepción, que van desde el ámbito de su casa -sobretodo en relaciones de pareja binacionales--, su relación con las Instituciones y la sociedad entera en general, situaciones que, por cuestiones de espacio, no puedo exponer. Quiero apuntar también que las situaciones presentadas en este texto de una manera generalizada, se ven agudizadas en mayor y menor medida según las características específicas que presenta cada migrante, como su nacionalidad, color de piel, procedencia étnica, clase, tipo de estatus legal en Alemania o la situación de ilegalización, características que las colocan en diferentes posiciones en un mapa jerárquico definido por las fronteras nacionales, étnicas y raciales en el orden global.

\section{A MANERA DE CONCLUSIÓN}

La investigación y el análisis teórico que he llevado a cabo durante mi investigación me han llevado a concluir, por un lado, que las mujeres migrantes latinoamericanas son actoras sociales y políticas que participan en la construcción de la diversidad de los procesos sociales migratorios en épocas de globalización. Por otro lado, que las persistentes fronteras nacionales, de género, étnicas y raciales las posicionan en un lugar subalterno en las sociedades dominantes del Norte, en su calidad de "mujeres/extranjeras/provenientes del Tercer mundo", en el marco de los actuales Estados nacionales, la migración internacional y el orden económico y geopolítico jerárquico global.

El estudio de caso que he expuesto con mujeres latinoamericanas migrantes a Alemania ejemplifica el papel protagónico que estas migrantes están jugando en la migración. A su vez, muestra las discriminaciones y estigmatizaciones sociales a las que son expuestas a través de su inscripción social en un mapa jerárquico global delineado por fronteras materiales y simbólicas. Quisiera dejar, a modo de reflexión, la forma en que las mujeres migrantes, precisamente, mediante su proceso de migración - de forma colectiva e/o individual-, rompen, reelaboran y se desplazan continuamente entre estas diferentes fronteras en que son inscritas. 


\section{BIBLIOGRAFÍA}

AGRELA, B.: La politica de Inmigración en España: reflexiones sobre la emergencia del discurso de la diferencia cultural. In: Migraciones Internacionales. Vol. 1, Múm. 2, COLEF, 2002. 93-122.

ANDERSON, B.: Die Erfindung der Nation, Frankfurt am Main/New York, Campus, 1988.

ANDRIJASEVIC, R.: I confini fanno la differenza: (Il)legalità, migrazione e tratta in Italia dall' est europeo, In: Studi Culturali, Anni I, No. 1, giugno, 2004.

ANZUÁLDA, G.: Borderlands/La Frontera. The New Mestiza, San Francisco, Spinters/Aunt Lute, 1987.

APITZSCH, U.: Migration und Traditionsbildung. In: Karpf, Ernst/Kiesel, Doron (Ed.), Politische Kultur und politische Bildung. Jugendliche ausländischer Herkunf, Frankfurt am Main, 1996, 11-30.

ARIZA, M.: Género y migración femenina: dimensiones análiticas y desafios metodológicos. In: Barrera/ Oehmichen (Ed), Migración y relaciones de género en México, México, GIMTRAP/ UNAM, 2000, 33-62.

AUFHAUSER, E.: Migration und Geschlecht: Zur Rekonstruktion von Weiblichkeit und Männlichkeit in der internationalen Migration. In: Karl Husa /Parnreiter/Stacher (Ed.), Internationale Migration, Frankfurt, 2000, 97-122.

CASTELLS, M.: Das Informationszeitalter II. Die Macht der Identität, Opladen, Leske+-Budrich, 2000.

CASTLES, S.; DAVIDSON, A.: Citizenship and Migration. Migration and the Politics of Belonging, New York, ROUTLEDGE, 2000.

CHANT, S.: Gender and Migration in Developing Countries, London and New York, Belhaven Press, 1992.

CURIEL, O.: Identidades esencialistas o construccion de identidades politicas: el dilema de las mujeres negras, Santo Domingo, FLACSO, 2003.

Erel, U.: Migrantinnen zwischen Anerkennung und Abqualifikation, In: Steyerl Hito Gutiérrez Rodríguez Encarnación (Ed), Spricht die Subalterne Deutsch, Münster, UNRAST, 2003, 108 128.

ESCALONA, M.: Diversidad Sexual, Migración e Identidad. Lesbianas latinoamericanas en Berlin. Ponencia presentada en el Congreso: „Latinos alla scoperta dell' Europa. Nuove migrazioni e suazi della cittadinanza“, Universidad de Genova, 2004.

GREGORIO, G.: Mujer espaniola, blanca, rica...: Trabajo de campo en inmigración y relaciones de género. In: Francisco Checa (Ed) Las migraciones a debate. Da las teorias a las prácticas sociales, Espania, Icaria, 2002.

GUTIÉRREZ RODRÍGUEZ, E.: Intellektuelle Migrantinnen-Subjetivitäten Zeitalter von Globalsierung, Opladen, Leske+Budrich, 1999.

GUTIÉRREZ RODRÍGUEZ, E.: Repräsentation, Subalternität und postkoloniale Kritik, In: Steyerl Hito Gutiérrez Rodríguez Encarnación (Ed), Spricht die Subalterne Deutsch, Münster, UNRAST, 2003, 17-37.

HAHN, S.: Wie Frauen in der Migration Geschichte verloren gingen. In: Karl Husa/Parnreiter/ Stacher (Ed.), Internationale Migration, Frankfurt, 2000, 77-95.

HARITAWORN, J.: Der ethnisirte Arbeitplatz als paradoxer Ort der Identifikation: Verhandlung von Rassismus, Sexismus, Klassismus und kultureller Identität in einem "thailändischen" Restaurant in Britannien, In: Castro Varela,

CLAYTON, D. (ed): Migration, Gender, Arbeitsmarki, Deutschland, Utrike Helma Verlag, 2003, 1.86-207. 
HERNÁNDEZ, B.; KRÖN, S.: Schatten im Paradies, In: Hernández Berenice (Ed.), Lateinamerikanische Migrantinnen in Deutschland. Presencia e Invisibilidad, Berlin, Bildungswerk Berlin der Heinrich-Böll-Stiftung, 2000, 6-10.

HERNÁNDEZ, B.: Mit halber Machete in die Kämpfe des Alltags- Lebensrealitäten und Überlebenstrategien von Migrantinnen. In: Arranca Núm. 26, 2003, 12-15.

Le Breton Baumgartner Maritza, Illegalisierung und Kriminalisierung der Migrantinnen. „Frauen Handel" im Kontext restriktiver Einwanderungspolitik. In Widerspruch Nr. 37/99, Zürich, 1999, 83-93.

MEZZADRA, S.: Diritto di fuga. Migrazione, cittadinanza, globalizzazione, Verona, Ombre Corte, 2001.

MOHANTY, C.T.: Under Western Eyes: Feminist Scholarship and Colonial Discourses. In C.T. Mohanty, A. Russo and L. Torres (eds.) Third World Women and the Politics of Feminism, Bloomington, Indiana Bloomington Press, 1991.

MOHANTY, C.T.: Under Western Eyes, Revisited: Feminist Solidarity through Anticapitalist Struggles, Journal of Women Culture and Society, vol. 28, no. 2, Winter 2003, 501- 535.

MOULIER, B.: Nicht länger Reservarmee. Thesen zur Autonomie de Migration und zum notwendigen Ende des Regimenes der Arbeitsmigration, Subtropen, 12/04, April 2002.

MOROKVASIK, M.: Jugoslawische Frauen. Die Emigration-und danach, Frankfurt am Main, 1987.

PRODOLLIET, S.: Spezifisch weiblich: Geschlecht und Migration. Ein Rublick auf der Migrationsforschung. In: Zeitschrift für Frauenforschung, Bielefeld, 1999, 26-42.

ROSINA JUANITA HENNING, Die Arbeit mit illegalen ausländischen Prostituirten in Frankfurt/ Main. In: Arranca!, Schwerpunkt: Identitäten, Nr. 20, Berlin, 2000, $22-24$.

SASSEN, S.: Migranten, Siedler, Flüchtlinge. Von der Massenauswanderung zur Festung Europa, Frankfurt am Main, Fischer, 2000.

SASSEN, S.: Metropolen des Weltmarkts. Die neue Rolle der Global Cities, Frankfurt/New York, Campus, 1996.

SCHÖTTES, M.; TREIBEL, A.: Frauen-Flucht-Migration. Wanderugsmotive von Frauen und Aufnahmesituation in Deutschland. In: Ludger Pries (Ed) Transnationale Migration, Soziale Welt Sonderband 12, 1997, 85-117.

VALENZUELA ARCE: El color de las Sombras. Chicanos, identidad y racismo, México, COLEF/Plaza y Valdés, 1998.

VELASCO ORTIZ, L.: El regreso de la comunidad: migración indigena y agentes étnicos. Los mixtecos en la frontera México- Estados Unidos, México, COLMEX, COLEF, 2002.

Woo, O.: Las mujeres migrantes: ¿Un tema olvidado o ignorado?. In: Estudios Sociales, Revista de Investigación del Noroeste, Vol. VI, Núm. 11, enero-junio, México, El Colegio de Sonora, 1996. 